\title{
Guidelines for the management of thrombophilia
}

Summary

Although there are numerous risk factors for venous thromboembolic disease, the term 'thrombophilia' refers only to those familial or acquired disorders of the haemostatic system that result in an increased risk of thrombosis. The inherited thrombophilias include antithrombin III deficiency, resistance to activated protein $\mathbf{C}$ (factor $\mathbf{V}$ Leiden), protein $\mathbf{C}$ and protein $\mathbf{S}$ deficiencies as well as some rare forms of dysfibrinogenaemia. It is possible that other inherited conditions might also predispose to thrombosis. In contrast, when using the above definition, the antiphospholipid syndrome is the only genuine acquired thrombophilic state. Patients who have thromboembolic disease at a young age with no provoking event or who have a positive family history or whose thrombosis involves an unusual site should be investigated for thrombophilia. The management of a patient identified as having a laboratory abnormality associated with thrombophilia will depend on a variety of factors such as the patient's individual and family thrombotic history, the site of the thrombosis and the presence of other prothrombotic risk factors. The use of prophylactic anticoagulation during pregnancy and the puerperium requires particularly careful consideration in thrombophilic women. As more becomes known about the thrombophilias it will become possible to formulate more exact guidelines as to the management of these conditions.

Keywords: guidelines, thrombophilia, thromboembolism prophylaxis

\footnotetext{
Department of Haematology, The Royal London Hospital, Whitechapel, London E1 1BB, UK

JD Cavenagh

BT Colvin
}

Correspondence to Dr JD Cavenagh

Accepted 15 July 1995

\author{
JD Cavenagh, BT Colvin
}

Thromboembolic disease, which can affect both arterial and venous vascular systems, represents one of the major worldwide causes of morbidity and mortality. Although any assessment is fraught with inaccuracies, the best population-based studies of incidence estimate that approximately 70000 cases of venous thromboembolic disease will be admitted to hospital in the UK each year. The in-hospital mortality is $12 \%$ and the three-year mortality reaches $30 \%{ }^{1}$ Venous thromboembolic disease is therefore an important medical problem. In recent years several inherited and acquired predisposing conditions for thromboembolic disease have been identified and the recognition of these entities presents challenges with respect to their appropriate management. This paper is largely restricted to venous thromboembolic disease because abnormalities of coagulation are better understood in this context. Arterial thromboembolism contributes to an even greater extent to mortality in the industralised world and risk factors within the haemostatic system are increasingly recognised as contributing significantly to the development of atheromatous arterial disease.

\section{Risk factors for venous thrombosis}

Numerous factors, both inherited and acquired, may predispose an individual to venous thromboembolic disease (box 1). Acquired factors may take the form of physiological processes, provoking events or specific pathologies. These distinctions are arbitrary and some factors may fall into more than one category. For instance, obesity has a genetic determinant and may well be considered a pathological process in its own right. Also, it is becoming increasingly clear that factors interact, often in a synergistic manner. Thus, individuals are much more likely to experience a post-surgical deep vein thrombosis if they already possess an inherited predisposition to thrombosis.

The term thrombophilia' is probably best used to refer to those familial or acquired disorders of the haemostatic system that result in an increased risk of thrombosis. ${ }^{2}$ A large number of inherited abnormalities of the haemostatic system have been proposed as potential causes of thrombophilia, with varying degrees of credibility. However, care must be taken to establish a genuine relationship between an inherited in vitro abnormality and thrombotic risk, since reporting bias is likely to overestimate any prothrombotic tendency. Familial thrombophilia can only be said to exist if an identified laboratory abnormality cosegregates with increased thrombotic risk within affected families after the propositi have been excluded. Such analysis has ruled out a variety of putative inherited thrombophilias such as factor XII deficiency, factor VII excess, heparin cofactor II deficiency, plasminogen deficiency, tissue plasminogen activator (tPA) deficiency and plasminogen activator inhibitor-1 (PAI-1) excess.

The excess risks associated with particular thrombophilic states are similarly hard to quantitate and the large prospective cohort studies which would be required to do so have not been performed. Estimates of risk can vary wildly depending on the exact group of individuals studied. Much higher estimates of thrombotic risk result if the families of affected patients rather than normal, randomly selected, individuals are analysed. This discrepancy may well result from distinct mutations with greater pathological potential being present in affected families or indeed from the coexistence of a second prothrombotic gene within such families. Another important factor is the method by which the incidence of thromboembolic disease is determined. A clinical, non-objective, diagnosis of venous thrombosis is accurate in only $50 \%$ of cases.

\section{The inherited thrombophilias}

The inherited thrombophilias that have so far been identified tend to result from defects in the naturally occurring systems that normally control and limit the haemostatic process. 


\begin{tabular}{|l|}
\hline Risk factors for venous \\
thrombosis \\
\hline Inherited risk factors \\
- antithrombin III deficiency \\
- resistance to activated protein C \\
(factor V Leiden) \\
- protein C deficiency \\
- protein S deficiency \\
- dysfibrinogenaemias \\
possible risk factors: raised factor \\
VIII level, raised fibrinogen level, \\
hyperhomocysteinaemia \\
Acquired risk factors \\
physiological factors: advancing \\
age, pregnancy and childbirth, \\
obesity \\
provoking events: surgery and \\
trauma, immobility \\
pathological factors: damage or \\
obstruction to the veins (including \\
previous thrombosis), \\
antiphospholipid syndrome, \\
malignancy (Trousseau's \\
syndrome), chemotherapy, \\
oestrogen therapy (including \\
contraceptive pills), nephrotic \\
syndrome, paroxysmal nocturnal \\
haemoglobinuria, thrombotic \\
thrombocytopenic purpura, \\
heparin-induced thrombocytopenia \\
and thrombosis syndrome, \\
myeloproliferative syndromes, \\
hyperviscosity syndromes \\
\hline
\end{tabular}

Box 1
ANTITHROMBIN III (AT-III) DEFICIENCY

AT-III is the most important member of the serine protease inhibitor (serpin) family involved in the control of haemostasis. It circulates in the plasma and binds to and inactivates a variety of activated serine proteases involved in haemostasis (thrombin or factor IIa, factors Xa, IXa, XIa, and XIIa). Its active site consists of a peptide sequence that is a 'dummy' substrate for activated serine proteases which therefore bind to but fail to cleave it, instead forming a stable complex that is rapidly removed from the circulation by the liver. The binding of heparin or heparin sulphate to a distinct domain within AT-III results in the molecule acquiring a much higher affinity for thrombin, factor $\mathrm{Xa}$ and the other serine proteases. As with deficiencies of any functional protein, AT-III deficiency is classified as Type I when subnormal quantities of a normal protein are present or as Type II when a functionally abnormal protein is produced. ${ }^{3}$ Mutations which result in Type II deficiency can involve the active site, the heparin-binding site or both. AT-III molecules with mutant heparin-binding sites result in a significantly lower risk of thrombosis than do the other abnormal forms. AT-III deficiency is transmitted as an autosomal dominant trait and homozygotes, except for those homozygous for mutations at the heparin-binding site, die in utero. Approximately $70 \%$ of patients with familial AT-III deficiency will experience venous thromboembolic disease during their lifetime. ${ }^{4}$ Thromboses tend to start at puberty, perhaps because of declining levels of $\alpha_{2}$ macroglobulin, an alternative thrombin inhibitor, which is relatively abundant during the first two decades of life. ${ }^{5}$ Women with familial AT-III deficiency are particularly susceptible to thrombosis during pregnancy $(18 \%$ risk) and the postpartum period ( $33 \%$ risk) ${ }^{6}$

\section{RESISTANCE TO ACTIVATED PROTEIN C (FACTOR V LEIDEN)}

The thrombomodulin-protein $\mathrm{C}$ anticoagulant mechanism is of fundamental importance in regulating normal haemostasis. Stimulation of the coagulation cascades results in the generation of thrombin which cleaves fibrinogen to form a fibrin clot. Thrombin has multiple actions and, when it is bound to the endothelial cell membrane molecule thrombomodulin, it cleaves the vitamin $\mathrm{K}$-dependent serine protease protein $\mathrm{C}$ to form activated protein $\mathrm{C}$ which, in turn, cleaves factors Va and VIIIa into inactive molecules and so inhibits coagulation. Protein S, another vitamin $\mathrm{K}$-dependent protein, is an important co-factor for activated protein $\mathrm{C}$ which probably acts by enhancing its ability to bind to the phospholipid membranes of platelets and endothelial cells where the factor Va- and VIIIa-containing complexes perform their enyzmatic functions.

The underlying defect responsible for familial resistance to activated protein $\mathrm{C}$ is a point mutation resulting in a single amino acid substitution at one of the two activated protein C-cleavage sites in factor $\mathrm{Va}$ (factor $\mathrm{V}$ Leiden).$^{7-9}$ Thus, in affected individuals, the coagulation system is rendered insensitive to the anticoagulant effects of activated protein C. Approximately $5 \%$ of the general population is heterozygous for this mutation and approximately $40 \%$ of patients with otherwise unexplained thrombosis possess it. ${ }^{10,11}$ Thus it is by far the most common known cause of inherited thrombophilia. Heterozygotes have a sevenfold increased risk of thromboembolic disease ${ }^{12}$ and $30 \%$ of such patients will have developed a thrombosis by 60 years of age. However, unlike other homozygous deficiencies, patients with homozygous factor $\mathrm{V}$ Leiden do not necessarily develop thromboembolic disease. Indeed, at 60 years of age, $40 \%$ of such individuals will still be thrombosis-free. ${ }^{13}$ It is becoming clear that this common variant frequently results in thromboembolic disease in the context of additional provoking factors or when another inherited risk factor is also present, such as protein $\mathrm{C}$ deficiency.

\section{PROTEIN C DEFICIENCY}

A large number of mutations result in protein $C$ deficiency. In particular, Type II deficiency can result from mutations affecting the thrombomodulin cleavage site, the serine protease domain or the glutamate-rich domain that is $\gamma$ carboxylated by vitamin $\mathrm{K}$-dependent enzymes. It is not surprising, therefore, that the clinical phenotype of 'protein $\mathrm{C}$ deficiency' can vary widely. In some severely affected kindreds, protein $\mathrm{C}$ deficiency results in a $75 \%$ chance of thromboembolic disease by the age of 60 years. ${ }^{14}$ In contrast, a study of normal blood donors revealed a $0.5 \%$ prevalence of protein $\mathrm{C}$ deficiency with a negligible incidence of thromboembolic disease. ${ }^{15}$ Different mutations clearly result in widely different clinical phenotypes which are not necessarily distinguishable by the results of in vitro assays. Indeed, an autosomal recessive form of the disease has been described, which results from the inheritance of two individually clinically silent mutations. 


\section{Case history}

A 22-year-old woman presented with headache, disorientation and weakness of the right side of the face. Papilloedema was found on examination. A computed tomography (CT) scan showed thrombus in the superior sagittal sinus. All other initial investigations were normal. She was treated with dexamethasone and acetazolamide and her neurological status slowly improved. Two weeks after hospital discharge she developed pleuritic chest pain and pulmonary embolism was diagnosed by ventilationperfusion scanning. She was treated with intravenous heparin and subsequently started on oral anticoagulation.

As treatment for acne, she had been taking a contraceptive pill with a high oestrogen content. Her father had developed a spontaneous deep-vein thrombosis at the age of 22 years but there was no other family history of thromboembolic disease.

Thrombophilia investigations were al negative and she was maintained on warfarin for the next seven years until she wished to become pregnant and the drug was stopped. She soon became pregnant and prophylaxis with adjusted dose heparin was initiated.

Repeated thrombophilia testing prior to commencing heparin revealed an AT-III level of $64 \%$ (borderline low). Genetic analyses revealed a point mutation in exon 4 resulting in Type I deficiency. Labour was induced at 38 weeks and the heparin reduced to standard prophylactic dosage. Just prior to delivery, AT-III $(40 \mathrm{IU} / \mathrm{kg})$ was infused and, after a normal vaginal delivery, warfarin was recommended. A cord sample from the baby girl had an equivocal AT-III level but genetic analysis revealed that she had not inherited the mutant gene.

This case highlights two points. Firstly, repeated testing is sometimes required in order to detect abnormalities of the haemostatic system since there is considerable physiological and pathological variability in the levels of these proteins. Secondly, the value of genetic analysis is demonstrated which, in this case, clinched a difficult diagnosis and also confirmed normality in the offspring.
Patients from affected families typically develop thromboembolic disease from the age of 20 years onwards. The half-life of protein $C$ is shorter than those of all the other vitamin K-dependent proteins (other than factor VII). Therefore, when warfarin therapy is commenced, there is a period of dramatically increased thrombotic risk which may be manifest as coumarin-induced skin necrosis. Concurrent heparin therapy is required to prevent this complication. Homozygous neonates are likely to develop neonatal purpura fulminans. ${ }^{16,17}$ Superficial thrombophlebitis is a characteristic feature of both protein $\mathrm{C}$ and protein $\mathrm{S}$ deficiencies.

\section{PROTEIN S DEFICIENCY}

Protein $S$ circulates in an active, free form $(40 \%)$ and as an inactive form bound to $\mathrm{C} 4 \mathrm{~b}$-binding protein (C4b-BP) $(60 \%)$. Only free protein $\mathrm{S}$ can act as a co-factor for activated protein $C$ and so any increase in C4b-BP will reduce protein $S$ activity. Since $\mathrm{C} 4 \mathrm{~b}-\mathrm{BP}$ is an acute phase reactant, any inflammatory process will result in a reduction in protein $S$ activity. Indeed, $20 \%$ of all hospitalised patients have low free protein $S$ levels. Deficiency has proved difficult to define at the molecular level because of the presence of a homologous pseudogene. In vitro, functional protein $\mathrm{S}$ deficiency can be confused with the much more common factor $V$ Leiden defect. Patients from affected families have up to a $70 \%$ risk of thrombosis by the age of 60 years and homozygously affected neonates develop neonatal purpura fulminans.

\section{DYSFIBRINOGENAEMIA}

Most mutations within the fibrinogen gene are clinically silent, some result in a bleeding tendency whilst others predispose to thromboembolic disease. There are a variety of molecular mechanisms which result in increased thrombotic risk, including abnormal thrombin binding and resistance to plasmin-mediated lysis. Although there are well-described families with inherited thrombophilia due to dysfibrinogenaemias, they are rare and the actuarial risk of thromboembolic disease is significantly lower than with the more well-recognised forms of inherited thrombophilia.

\section{OTHER POTENTIAL INHERITED THROMBOPHILIAS}

Raised levels of fibrinogen are well known to be a risk factor for arterial thrombosis and indeed a large population-based case-control study has demonstrated that a fibrinogen concentration $>5 \mathrm{~g} / 1$ results in a four-fold increased relative risk of thromboembolic disease..$^{18}$ The level of fibrinogen may well be partly genetically determined. Similarly, raised levels of factor VIII are associated with thromboembolic disease and there is likely to be polymorphic, genetically determined regulation of factor VIII expression. ${ }^{19}$ Certainly, patients with haemophilia $\mathrm{A}$ are most unlikely to develop thromboembolic disease. The inborn error of metabolism homocystinuria has long been recognised as being associated with an increased risk of thromboembolic disease. More recently, hyperhomocysteinaemia (which is due to genetic variation in levels of gene expression) has been implicated as a risk factor for thrombosis. ${ }^{20}$ It is proposed that raised levels of this amino acid result in endothelial dysfunction and disturbed protein $\mathrm{C}$ activation by the thrombin-thrombomodulin pathway. These recently identified risk factors confer a relatively low probability of thromboembolic disease on 'affected' individuals. However, they appear to be important in population terms and may well be examples of those second factors that are required for the development of thrombosis in patients with other, better described, inherited thrombophilias.

Table 1 Initial investigations

\begin{tabular}{lll}
\hline Investigation & Potential diagnoses & Laboratory abnormality \\
\hline $\begin{array}{l}\text { Full blood count } \\
\text { and blood film }\end{array}$ & $\begin{array}{l}\text { polycythaemia rubra vera } \\
\text { essential thrombocythaemia } \\
\text { paroxysmal nocturnal } \\
\text { haemoglobinaemia } \\
\text { hyperviscosity }\end{array}$ & $\begin{array}{l}\text { raised haematocrit } \\
\text { raised platelet count } \\
\text { anaemia and polychromasia }\end{array}$ \\
$\begin{array}{l}\text { Prothrombin time } \\
\begin{array}{l}\text { Activated partial thrombo- } \\
\text { plastin time (APTT) }\end{array}\end{array}$ & lupus anticoagulant \\
$\begin{array}{l}\text { Thrombin time (TT) } \\
\text { rhrouleaux }\end{array}$ & dysfibrinogenaemias & $\begin{array}{l}\text { prolonged APTT (in some } \\
\text { cases) } \\
\text { shortened/prolonged TT }\end{array}$ \\
\hline
\end{tabular}




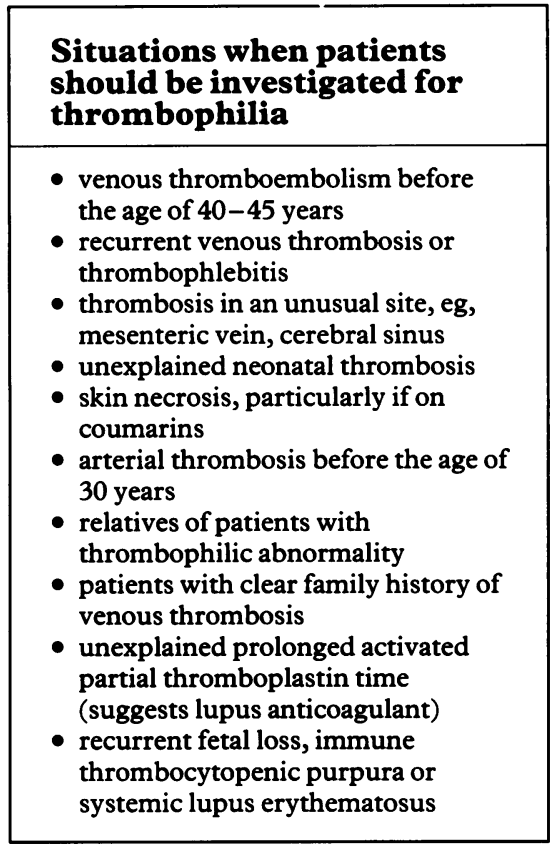

Box 2

\section{Case history}

A 25-year-old man presented with occipital headache and neck pain and rapidly developed diplopia. Examination revealed papilloedema, bilateral VIth nerve palsies and pyramidal weakness of the left arm. Sagittal sinus thrombosis was confirmed by digital subtraction angiography. Initial screening tests were all normal as were thrombophilia investigations. He was treated with intravenous heparin followed by warfarin and he slowly improved, although there was a residual left VIth nerve palsy.

Six months later, whilst still on warfarin, he was found to be protein C deficient. His mother was also found to have low protein $C$ and had had three deep-vein thromboses. She declined oral anticoagulation because she had experienced a serious psoas haematoma whilst previously on warfarin.

This case again demonstrates the frequent necessity for repeated testing in order to diagnose thrombophilic states. Also, it shows that protein C deficiency can be detected when patients are taking warfarin. Although thrombophilia testing is ideally performed when patients are off all anticoagulants, in some cases it is deemed imprudent to stop warfarin. So long as the patient is tested when oral anticoagulation is stable, a disproportionately low level of protein C compared to the other vitamin $\mathrm{K}$-dependent coagulation proteins suggests protein $\mathrm{C}$ deficiency. It is important to attempt to make the diagnosis in these circumstances so that family members can be investigated when appropriate.

\section{Acquired thrombophilia}

Although there are many important acquired risk factors for thrombosis, few are genuine thrombophilias as defined above, except for the antiphospholipid syndrome. This entity is defined by the presence of antiphospholipid antibodies (a lupus anticoagulant or anticardiolipin antibodies) in conjunction with certain clinical events such as recurrent arterial and venous thrombosis, thrombocytopenia or recurrent fetal loss. ${ }^{21,22}$ This syndrome can be primary, or secondary to systemic lupus erythematosus and other autoimmune diseases, drugs or various infections including HIV. The pathogenesis of thrombophilia may vary between individuals and may involve reduced endothelial prostacyclin production or impaired protein $\mathrm{C}$ activation.

\section{Which patients to investigate for thrombophilia?}

Venous thrombosis is an extremely common problem and extensive investigation for thrombophilia should only be undertaken in patients with features which suggest a prothrombotic tendency. This is important not only because expensive laboratory work is to be avoided when it is unnecessary, but also because universal screening of patients with thromboembolic disease will result in a large number of 'false positive' results. For instance, up to $3 \%$ of a normal population may have laboratory evidence of protein $\mathrm{C}$ deficiency but these individuals are unlikely to have a significant thrombophilia. ${ }^{15}$

The British Committee for Standards in Haematology has published guidelines $^{2}$ as to which patients should be investigated for thrombophilia (box 2). Illustrative cases (case histories) highlight some of the important issues about which patients should be selected for investigation.

\section{Investigations}

The initial assessment of any patient with thrombosis should be directed at determining if there is any overt risk factor for thromboembolic disease. The history and physical examination may highlight evidence suggestive of underlying malignant disease, autoimmune disease, nephrotic syndrome or myeloproliferative disorder. An initial screen will suggest further diagnoses (table 1). If no diagnosis has been made and thrombophilia is still suspected, then more elaborate haemostatic investigations are indicated (table 2). A large number of diagnostic pitfalls exist, and these must be considered before a diagnosis of an inherited thrombophilia is made (table 3). As can be seen, a large number of conditions can result in acquired deficiencies of natural anticoagulants. Since reduced levels are found at the time of an acute thromboembolic event and since heparin can reduce AT-III and warfarin can reduce protein $C$ and protein $S$ levels, thrombophilia investigations should ideally be performed when the patient is off all anticoagulants and at a time remote from the thrombotic event. Normal ranges vary according to age and sex (as is well recognised with protein C), and neonates have particularly low levels of protein C, protein S and AT-III. Protein $S$ levels are reduced in normal pregnant women and can reach levels that are usually associated with inherited protein $S$ deficiency. ${ }^{23}$

Any positive investigation must be repeated at least once before a firm diagnosis can be made in order to rule out technical error or biological variability. For instance, a lupus anticoagulant can develop transiently after certain viral infections. Finally, if a potentially inheritable defect is detected, then thought should be given to the testing and counselling of family members.

Table 2 Investigations for thrombophilia

\begin{tabular}{ll}
\hline Investigation & Comment \\
\hline $\begin{array}{l}\text { Resistance to activated protein C } \\
\text { Genetic analysis for factor V Leiden }\end{array}$ & \\
$\begin{array}{l}\text { AT-III (functional assay) } \\
\text { Protein C (functional assay) } \\
\text { Protein S (antigenic assay) }\end{array}$ & $\begin{array}{l}\text { will detect Type I \& II deficiencies } \\
\text { will detect Type I \& II deficiencies } \\
\text { functional assays give false positive results in the } \\
\text { presence of factor V Leiden. }\end{array}$ \\
$\begin{array}{l}\text { lever Free protein S } \\
\text { lupus anticoagulant }\end{array}$ & $\begin{array}{l}\text { the antiphospholipid syndrome may be } \\
\text { Anticardiolipin antibodies }\end{array}$ \\
& $\begin{array}{l}\text { associated with a lupus anticoagulant, } \\
\text { anticardiolipin antibodies or both }\end{array}$ \\
\hline
\end{tabular}




\begin{tabular}{|l|}
\hline The investigation of \\
potential thrombophilia \\
\hline All patients with venous thrombosis \\
- treat with anticoagulants in the \\
standard manner \\
- assess the patient for the presence \\
of any risk factors and, if present, \\
manage accordingly \\
Does the patient fall into any of the \\
categories listed in box 2 ? \\
- No: no further investigation \\
required \\
- Yes: does the nature or extent of the \\
thrombosis warrant life-long \\
anticoagulation in its own right (eg, \\
sagittal sinus thrombosis)? If so, \\
attempts can be made to diagnose \\
thrombophilia whilst the patient is \\
on warfarin and family members \\
can be tested. If not, then: \\
Perform thrombophilia testing at least 3 \\
weeks after cessation of warfarin \\
- initial screening tests (full blood \\
count, blood film, platelets, \\
activated partial thromboplastin \\
time, thrombin time) \\
- thrombophilia tests (resistance to \\
activated protein C, factor V \\
Leiden, AT-III, protein C, protein \\
S, lupus anticoagulant, \\
anticardiolipin antibodies) \\
- if a positive result is obtained, the \\
test must be repeated at least once \\
before the laboratory abnormality is \\
confirmed \\
remember thaboratory abnormality (50\% of \\
patients who are included in box 2 \\
will have no such abnormality) does \\
not mean that thrombophilia does \\
not exist \\
transient \\
- consider the potential causes of \\
acquired deficiencies of AT-III, \\
protein C and protein $S$ (table 3 ) \\
in certain circumstances, attempt to \\
define the precise molecular defect \\
(eg, factor V Leiden, Type II \\
AT-III deficiences involving the \\
heparin-binding site) \\
\hline
\end{tabular}

Box 3
Table 3 Causes of acquired deficiencies of AT-III, protein C and protein S

\begin{tabular}{lll}
\hline Factor & Decreased production & Increased destruction \\
\hline AT-III & liver disease & DIC \\
& oestrogens & acute thrombosis \\
& & heparin therapy \\
& & nephrotic syndrome \\
& & drugs (asparaginase) \\
Protein C & liver disease & DIC \\
& warfarin & acute thrombosis \\
Protein S & liver disease & DIC (asparaginase) \\
& warfarin & acute thrombosis \\
& pregnancy & drugs (asparaginase) \\
& oestrogens & raised C4b-BP(inflammation)
\end{tabular}

DIC $=$ disseminated intravascular coagulation

\section{The management of thrombophilia}

If all patients with thromboembolic disease less than 45 years of age with no readily identifiable cause for thrombosis are fully investigated as above, then approximately $5 \%$ will be found to be deficient in AT-III, protein C and protein $\mathrm{S}$, respectively. A further $40 \%$ will have resistance to activated protein $\mathrm{C}$. Therefore, approximately half of the patients suspected of having thrombophilia will have no detectable haemostatic defect, and it is important to appreciate that this does not mean that they are not thrombophilic, or indeed that they do not have familial thrombophilia. In these cases only an individual assessment of the patient's and his or her family's thrombotic history will enable one to propose a rational management plan. It seems highly probable that further genetic abnormalities resulting in thrombophilia will be discovered in the future.

\section{THE ACUTE THROMBOEMBOLIC EVENT}

In virtually all cases, the management of a first thrombotic event in a thrombophilic patient will be identical to that of all other patients since the diagnosis of thrombophilia is not usually made until after warfarin has been stopped. The observation of heparin resistance should alert the clinician to the possibility of AT-III deficiency. If a thrombosis occurs in an individual who is known to come from a protein $\mathrm{C}$ or protein $\mathrm{S}$ deficient kindred, then extra care must be taken to ensure that warfarin is introduced under heparin cover to prevent coumarin-induced skin necrosis. If neonatal purpura fulminans is suspected, then protein $\mathrm{C}$ and protein $\mathrm{S}$ assays should be performed urgently and, if profound protein $\mathrm{C}$ deficiency is confirmed $(<1 \%)$, then protein $\mathrm{C}$ concentrates should be administered. ${ }^{17}$ This unusual and very serious condition has been treated successfully by regular protein $\mathrm{C}$ concentrate infusions, oral anticoagulation and also by liver transplantation.

\section{LIFE-LONG ANTICOAGULATION}

An accepted strategy in general hospital practice is to manage a first thrombosis with three months' and a second with twelve months' oral anticoagulation. A third thrombosis labels a patient as suffering from recurrent venous thrombosis and life-long anticoagulation is usually recommended. This is a reasonable basis on which to plan management for patients with thrombophilia.

When a patient who is known to have a laboratory abnormality associated with thrombophilia suffers a second thromboembolic event, life-long anticoagulation should be considered. This recommendation takes into account the greatly increased risks of recurrent thromboembolic disease in this group. However, it is important to bear in mind that thrombophilic families exist who have no identifiable laboratory abnormality and the management of individuals from such families will be determined by each individual's and their family's thrombotic history.

There are certain circumstances when life-long anticoagulation should be considered after only one thrombotic event. A very high risk of a second thrombosis in patients with the antiphospholipid syndrome has recently been highlighted, and for this group of patients life-long oral anticoagulation (INR 3-4.5) has been recommended after one thrombotic event. ${ }^{24}$ Various other factors are important in assessing any individual case. AT-III deficiency results in a greater thrombotic risk that protein $C$ or protein $S$ deficiency, although there is considerable variability within kindreds with AT-III deficiency, since some 


\section{The management of thrombophilia \\ 1 A first thrombosis in patients included in box 2 \\ Antiphospholipid syndrome - advise life-long oral anticoagulation (INR 3-4.5) \\ AT-III deficiency \\ - consider life-long oral anticoagulation (INR 2-3) unless Type II deficiency \\ - advise adjusted-dose heparin ${ }^{\star}$ through pregnancies and oral anticoagulation for at least 6 weeks ${ }^{\star \star}$ post-partum. Infuse AT-III concentrate just prior to delivery whilst reducing heparin dosage to routine prophylactic

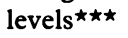 \\ - advise prophylactic anticoagulation for any subsequent high-risk situations}

\section{Protein C deficiency, protein S} deficiency and resistance to activated protein $\mathbf{C}$

- consider life-long oral anticoagulation (INR 2-3) only in specific circumstances such as after a life-threatening thromboembolic event, with an immobile life-style, with a strong family history of serious thromboembolic events or coexistence of more than one abnormality

- initiation of warfarin therapy must be covered by heparin in protein $\mathrm{C}$ or protein $S$ deficiency

- if the thrombotic event was spontaneous, then advise adjusted-dose heparin throughout pregnancy and oral anticoagulation for 6 weeks post-partum

- if the thrombotic event was during or after a previous pregnancy, then advise routine prophylactic anticoagulation during the first trimester followed by adjusted-dose heparin until delivery when heparin should be reduced and substituted by warfarin for 6 weeks post-partum

- advise prophylactic anticoagulation during subsequent high-risk situations

- advise against the use of the combined contraceptive pill

\section{No laboratory abnormality} detected

- management should be as for protein $\mathrm{C}$ or protein $\mathrm{S}$ deficiencies and resistance to activated protein C although the risks of recurrent thromboembolic disease may well be lower in this group than for those patients with defined laboratory abnormalities

- be guided by any family history of thromboembolic disease

continued have clinically mild mutations. Determination of the exact AT-III genetic abnormality may be of help in this situation. The severity of the initial thrombotic event is clearly relevant and the management of a patient after sagittal sinus thrombosis, for instance, will tend to be more aggressive than after a femoral deep-vein thrombosis. Another important factor is whether the thrombosis was spontaneous or provoked by one of many well known precipitants. Spontaneous events carry a higher risk of recurrence. The family history is of great relevance: if there has been a sequence of life-threatening events in a particular kindred, then there will be a low threshold for continuing anticoagulation in a newly recognised affected member with thrombosis, although it is important to remember that significant intra-family variation exists, presumably due to the presence or absence of coinherited predisposing abnormalities or environmental differences. If the patient has a sedentary, or perhaps wheelchairbound, lifestyle, then again there will be a lower threshold for continued warfarin therapy. Finally, if a female patient wishes to conceive, this should be a major consideration in management since it is important to avoid warfarin during pregnancy (see below).

In summary, it would be foolish to state firm guidelines for long-term oral anticoagulation in patients with a recognised haemostatic abnormality (or indeed for patients with thrombophilia with no such recognised abnormality). Wide variability in thrombotic risk exists within 'single' diagnostic categories as is clearly evident in AT-III and protein C deficiency. Furthermore, the coinheritance of secondary risk factors or the acquisition of disease or lifestylerelated risk factors make any generalisations unreliable. One must consider all the relevant facts in each case and make a clinical judgement as to the relative advantages and disadvantages of continued anticoagulation.

\section{PREGNANCY}

Pregnancy and conception present particular problems for any woman on long-term warfarin (whether because of a mechanical heart valve or thrombophilia). Warfarin possesses several unwanted potential side-effects which make it an unattractive drug for use during pregnancy ${ }^{25}$ Firstly, it can result in coumarin-induced embryopathy (nasal hypoplasia and stippled epiphyses) with maximum risk from weeks 6-12 of pregnancy. Secondly, it is associated with an increased risk of various central nervous system abnormalities which can result from warfarin use at any time during pregnancy. Thirdly, its use carries the risk of fetal bleeding, in particular of intracranial bleeding during delivery. Although the long-term use of heparin has several unwanted effects for the mother (namely the risk of thrombocytopenia and osteoporosis), it is probably the safest anticoagulant to use during pregnancy. ${ }^{26}$ Ideally, any conception should be planned and a strategy formulated. A possible approach is to stop warfarin when attempting to conceive and to continue on subcutaneous heparin until delivery. Since it may take several months to conceive, this approach may result in quite prolonged periods of heparinisation with its attendant problems. Another approach is to remain on warfarin and to perform frequent pregnancy tests. As soon as pregnancy is detected, the woman can then switch to subcutaneous heparin.

For women without recognised thrombophilia ${ }^{27}$ it is generally recommended that, if a previous thrombotic event occurred during the puerperium, subcutaneous heparin should start at delivery and warfarin should be used for six weeks post-partum. Conversely, if the thrombosis occurred during pregnancy itself, then heparin should start four to six weeks before the gestational stage at which it occurred previously and warfarin should again be used for six weeks post-partum. If a woman has had a thrombosis not related to pregnancy or any other recognised provocative event, then consideration should be given to the prophylactic use of heparin throughout pregnancy or restricted to the third trimester with subsequent warfarin for six weeks. These guidelines also provide a reasonable basis for the management of pregnancies in women with recognised thrombophilic abnormalities.

Women with AT-III deficiency appear to be at particularly high risk, even if they themselves have never experienced thromboembolic disease. ${ }^{6}$ Such women may be offered adjusted-dose heparin prophylaxis throughout pregnancy, followed by warfarin for a minimum of six weeks, in addition to infusion of AT-III concentrate ${ }^{28}$ just prior to delivery so that the heparin dosage can be reduced at the time of maximum haemostatic challenge. However, it is clear that the risks are much lower with deficiencies involving the heparin-binding site and these women probably do not require prophylaxis if they have never experienced venous thrombosis. Furthermore, if large analyses of normal populations are undertaken, AT-III deficiency is detectable in 1 in 600 people and virtually all of these have 'harmless' deficiencies. ${ }^{29}$ Therefore, it is clear that the management of 
/box 4 continued

\section{A second thrombosis in} patients included in box 2

AT-III deficiency, protein C deficiency, protein $S$ deficiency and resistance to activated protein C

- advise life-long oral anticoagulation (INR 2-3)

- initiation of warfarin therapy must be covered by heparin in protein $C$ and protein $\mathrm{S}$ deficiency

\section{No laboratory abnormality} detected

- Management must be based on individual and family history of thromboembolic disease

\section{Asymptomatic family members} with laboratory abnormality

\section{AT-III deficiency}

- advise adjusted dose heparin throughout pregnancy and warfarin for at least 6 weeks post-partum, except for the relatively benign Type II defects

- advise prophylaxis during high-risk situations

- avoid the combined contraceptive pill

Protein C deficiency and protein

$S$ deficiency

- advise prophylaxis during high-risk situations

- consider the family history when advising about subsequent pregnancies

- the combined contraceptive pill is probably safe with protein $S$ deficiency but should be avoided in protein C. deficiency until more data are available

\section{Resistance to activated protein C}

- the risks of thrombosis are much lower than in the other identifiable groups

- a low threshold for prophylaxis should exist, especially for those individuals with a strong family history

- the combined contraceptive pill should be avoided if other contraception is acceptable ${ }^{33}$

*Adjusted dose heparin: heparin 12 hourly subcutaneously, dose adjusted to achieve an activated partial thromboplastin time which is just prolonged when tested 4-6 hours after injection. There is limited experience of the use of low molecular weight heparin during pregnancy. $\star \star$ Anticoagulation during the puerperium warfarin (INR 2-3) for a minimum of six weeks

$\star \star \star$ Prophylactic anticoagulation during pregnancy: heparin 5000-7500 IU 12 hourly subcutaneously

Box 4 individuals who are found to have potentially thrombophilic deficiencies during 'routine' screening should not be equated with that of asymptomatic individuals who are identified from families with a thrombophilic history.

Women with protein $\mathrm{C}$ or protein $\mathrm{S}$ deficiency who have previously had a thrombosis should receive prophylaxis during pregnancy. Women who have had a thrombotic episode during late pregnancy or the puerperium may receive low-dose heparin until the third trimester when adjusted dose heparin should commence. Women who have had a spontaneous thrombosis unrelated to pregnancy should receive adjusted dose heparin throughout pregnancy as with AT-III deficiency. The final subset of women with protein C or protein $S$ deficiency who require consideration are asymptomatic individuals who have been detected following the identification of an affected family member. In this case, a clinical judgement will have to be made in the light of the kindred's family history of thrombosis and after counselling the affected woman. The risk of thromboembolic disease during pregnancy in women with resistance to activated protein $\mathrm{C}$ with no previous thrombosis is not clear at the present time and firm guidelines cannot be given. ${ }^{30}$

Women with the anti-phospholipid syndrome and prior thromboembolic disease should receive adjusted doses of heparin throughout pregnancy. The problem of recurrent fetal loss is a distinct one and optimal management remains unresolved. Trials are under way comparing the relative benefits of aspirin, heparin and steroids.

In summary, prescriptive guidelines are not possible. Each individual case must be considered on its own merits and a management decision made after full discussion with the affected woman. Indeed, the decision-making process may become even more difficult as more women are found to have laboratory 'abnormalities' that are known to be associated with thrombophilia in some kindreds, but which also have a relatively high frequency in the general population.

\section{PROPHYLAXIS DURING HIGH-RISK PERIODS}

For individuals who are known to have a laboratory abnormality associated with thrombophilia and who are not already receiving oral anticoagulation, there should be a very low threshold for recommending anticoagulant prophylaxis during periods of high risk for thromboembolism such as operations, immobility and after trauma. Indeed, one of the main reasons for identifying affected relatives of patients with thrombophilia is to be able to offer them advice about prophylaxis.

\section{FURTHER COUNSELLING}

Several issues should be discussed with affected individuals and asymptomatic family members who are found to possess a thrombophilic laboratory abnormality. The advisability of prophylaxis during high-risk periods should be discussed and the reversal of potentially avoidable risk factors encouraged, such as smoking and obesity. The use of the combined oral contraceptive pill should generally be discouraged if alternative methods of contraception are acceptable. There is evidence that women with AT-III deficiency are at increased risk of thromboembolic disease whilst using the contraceptive pill although women with protein $S$ deficiency have no increased risk whilst taking a low-oestrogen pill and there is currently not enough evidence available to comment on women with protein $\mathrm{C}$ deficiency ${ }^{31}$ For all groups, the progesterone-only pill is probably safe. Hormone replacement therapy for post-menopausal women appears to be safe. The oestrogen component of hormone replacement therapy is lower than most contraceptive pills and hormone replacement therapy confers considerable advantages with respect to cardiovascular mortality and the development of osteoporosis.

\section{Conclusion}

Guidelines for the management of thrombophilia are becoming clearer as more is learnt about the molecular mechanisms and natural histories of the various underlying disorders. Some suggested guidelines for testing and management of thrombophilia are outlined in boxes 3 and 4 . Although reasonably firm guidelines are possible in certain situations (eg, recurrent thrombosis in patients with a recognised thrombophilic laboratory abnormality), it is not possible to give advice of proven validity in many other circumstances. For instance, there are many individuals with unexplained thrombosis with no apparent predisposition (see box 2) who do not have any laboratory abnormality. It seems probable that new molecular defects will be discovered that might explain the thrombotic predisposition in this group of individuals, as indeed occurred when resistance to 
1 Anderson FA, Brownell Wheeler $\mathrm{H}$, et al. A population-based perspective of the hospital incidence and case-fatality rates of deep vein thrombosis and pulmonary

2 British Committee for Standards in

Haematology. Guidelines on the investigation Haematology. Guidelines on the investigation and management of th

3 Olds RJ, Lane DA, Thein SL. The molecular genetics of antithrombin deficiency. $\mathrm{Br} J$ Haematol 1994; 87: 221-6.

4 Thaler E, Lechner K. Antithrombin III deficiency and thromboembolism. Clin Haematol 1981; 10: 369-90.

5 Mitchell L, Piovella F, Ofosu F, Andrew M. $\alpha_{2}$-Macroglobulin may provide protection from thromboembolic events in antithrombin IIIdeficient children. Blood 1991; 78: 2299-304.

6 Conard J, Horellou MH, Van Dreden P, Lecompte T, Samama M. Thrombosis and pregnancy in congenital deficiencies of AT III, pregnancy in congenital deficiencies of AT III, protein C or protein S: study of
Thromb Haemost 1990; 63: 319-24.

7 Dahlback B, Carlsson M, Svensson PJ. Familial thrombophilia due to a previously unrecognised mechanism characterised by poor anticoagulan response to activated protein C: prediction of cofactor to activated protein C. Proc Natl Acad Sci USA 1993; 90: 1004-8.

8 Voorberg J, Roelse J, Koopman R, et al. Association of idiopathic venous thromboem-
bolism with single point-mutation at $\mathrm{Arg}^{506}$ of factor V. Lancet 1994; 343: 1535-8.

9 Bertina RM, Koeleman BPC, Koster T, et al. Mutation in blood coagulation factor $\mathrm{V}$ associated with resistance to activated protein $\mathrm{C}$. Nature 1994; 369: 64-7.

10 Svensson PJ, Dahlback B. Resistance to activated protein $\mathrm{C}$ as a basis for venous throm bosis. N Engl f Med 1994; 330: 517-22.

11 Beauchamp NJ, Daly ME, Hampton KK, Cooper PC, Preston FE, Peake IR. High prevalence of a mutation in the factor $\mathrm{V}$ gene within the UK population: relationship to activated protein $\mathrm{C}$ resistance and familial thrombosis. Br $\mathcal{F}$ Haematol 1994; 88: 219-22.

activated protein $\mathrm{C}$ was first described. Meanwhile, after due consideration of such a patient's personal and family thrombosis history, a clinical judgement has to be made on an individual basis as to any long-term anticoagulation or prophylaxis. All of the guidelines discussed above are based on risk analyses of individuals who have suffered a venous thrombosis or are the asymptomatic affected family members of such thrombotic individuals. In population terms this is a highly selected group and it is becoming clear that large-scale screening exercises of the general population will detect a very large number of people who have detectable abnormalities of the haemostatic system but no personal or family history of thrombosis. At the present time counselling such individuals remains very difficult and will remain so until more is known about the natural histories associated with specific defects.

12 Koster T, Rosendaal FR, de Ronde H, Briet E, Vandenbroucke JP, Bertina RM. Venous thrombosis due to poor anticoagulant response to activated protein C: Leiden thrombophilia to activated protein C: Leiden th
study. Lancet 1993; 342: 1503-6.

13 Greengard JS, Eichinger S, Griffin JH, Bauer KA. Brief report: variability of thrombosis KA. Brief report: variability of thrombosis among homozygous siblings with resistance to activated protein C due to an Arg-Gln mutation in the gene
$1559-62$.

14 Allaart CF, Poort SR, Rosendaal FR, Reitsma PH, Bertina RM, Briet E. Increased risk of venous thrombosis in carriers of hereditar protein C deficiency defect. Lancet 1993; 341: 134-8.

15 Miletich J, Sherman L, Broze G. Absence of thrombosis in subjects with heterozygous protein $C$ deficiency. $N$ Engl $\mathcal{f}$ Med 1987; 317: tein $691-6$.

16 Marcianack E, Wilson HD, Marlar RA Neonatal purpura fulminans: a genetic disorder Neonatal purpura fulminans: a genetic disorder related to the absence
Blood 1985; 65: 15-20.

17 Dreyfus M, Magny JF, Bridey F, et al. Treatment of homozygous protein $\mathrm{C}$ deficiency and neonatal purpura fulminans with a purified protein C concentrate. $N$ Engl $\mathcal{Y}$ Med 1991; 325: 1565-8.

18 Koster T, Rosendaal FR, Reitsma PH, van der Velden PA, Briet E, Vandenbroucke JP. Factor VII and fibrinogen levels as risk factors for venous thrombosis. Thromb Haemost 1994; 71: 719-22.

19 Koster T, Blann AD, Briet E, Vandenbroucke JP, Rosendaal FR. Role of clotting factor VIII in effect of von Willebrand factor on occurrence of effect of von Willebrand factor on occurrence of

20 Deep-vein thrombosis. Lancet 1995; 345: 152-5. hyperhomocysteinaemia a risk factor for recurrent venous thrombosis. Lancet 1995; 345: $882-6$

21 Hughes GRV. The antiphospholipid syndrome: ten years on. Lancet 1993; 342: 341-4

22 Khamashta MA, Hughes GRV. Antiphospholipid syndrome. A common cause of thrombosis. $B M \mathcal{F}$ 1993; 307: 883-4.
23 Comp PC, Thurnau GR, Welsh J, Esmon CT. Functional and immunological protein $S$ levels are decreased during pregnancy. Blood 1986; 68: $881-5$.

24 Khamashta MA, Cuadrado MJ, Mujic F, Taub NA, Hunt BJ, Hughes GRV. The management of thrombosis in the antiphospholipid-antibody of thrombosis in the antiphospholipid-antibody

25 Hyndrome. N Engl f Med 1995; 332: 993-7. 1991; 324: 1865-75.

26 Hirsh J. Heparin. N Engl f Med 1991; 324: 1565-74.

27 British Committee for Standards in Haematology. Guidelines on the prevention, investigation and management of thrombosis associated with pregnancy. $\mathcal{F}$ Clin Pathol 1993 46: 489-96.

28 De Stefano V, Leone G, De Carolis S, et al. Management of pregnancy in women with antithrombin III congenital defect: report of four cases. Thromb Haemost 1988; 59: 193-6.

29 Tait RC, Walker ID, Perry DJ, et al. Prevalence of antithrombin deficiency in the healthy population. Br $\mathcal{F}$ Haematol 1994; 87: 106-12.

30 Cook G, Walker ID, McCall F, Conkie JA, Greer IA. Familial thrombophilia and activated protein $C$ resistance: thrombotic risk in pregnancy? Br $\mathcal{F}$ Haematol 1994; 87: 873-5.

31 Pabinger I, Schneider B and the GTH study group on natural inhibitors. Thrombotic risk of women with hereditary antithrombin III-, protein $\mathbf{C}$ - and protein S-deficiency taking oral contraceptive medication. Thromb Haemost 1994; 71: 548-52.

32 Cooper PC, Hampton KK, Makris M, Abuzenadah A, Paul B, Preston FE. Further evidence that activated protein $C$ resistance can be misdiagnosed as inherited functional protein be misdiagnosed as inherited functional protein

33 Vandenbroucke JP, Koster T, Briet E, Reitsma Vandenbroucke JP, Koster T, Briet E, Reitsma
PH, Bertina RM, Rosendaal FR. Increased risk of venous thrombosis in oral-contraceptive users who are carriers of factor V Leiden. Lancet 1994; 344: 1453-7. 